\title{
Small differences in age and cataract surgery percentage have a potentially high effect on the corneal endothelial cell density
}

\author{
Yu Cheol Kim
}

Received: 4 February 2015/Accepted: 4 August 2015/Published online: 7 August 2015

(C) Springer Science+Business Media Dordrecht 2015

To the Editor,

I read with interest the article entitled "Differences in corneal parameters between normal tension glaucoma and primary open-angle glaucoma" by Lee et al. [1]. The study showed that the baseline characteristics such as age, anti-glaucoma medication, cataract surgery, and post-treatment intraocular pressure (IOP), which may affect endothelial cell density (ECD), were statistically similar in both their normal tension glaucoma (NTG) and primary open-angle glaucoma (POAG) populations, and the mean corneal ECDs in NTG and POAG subjects were 2380 and $2530 \mathrm{cell} / \mathrm{mm}^{2}$, respectively. On the basis of these results, the authors reported a significant lower corneal ECD in NTG, compared to POAG subjects with similar baseline characteristics. However, I respectfully disagree. The difference of ECD in the 2 groups can be due to differences in age and pseudophakic/ phakic ratio in the groups, though not statistically significant. The mean ages of the NTG and POAG were 67.6 and 61.8, respectively, and the pseudopha$\mathrm{kic} /$ phakic ratios were 0.2 and 0.1 , respectively. ECD reduction every year was reported as $0.3-1 \%$ and a recent study reported that the mean ECD difference between sixties and seventies age groups was 177 cells $/ \mathrm{mm}^{2}$ [2]. Approximately, $150 \mathrm{cell} / \mathrm{cm}^{2}$ of ECD difference is presumed to be due to 5.8 years of age difference and twice pseudophakia/phakia ratio not due to NTG.

\section{Compliance with ethical standards}

Conflict of interest The author declares that there is no conflict of interests regarding the publication of this article.

\section{References}

1. Lee JW, Wong RL, Chan JC, Wong IY, Lai JS (2014) Differences in corneal parameters between normal tension glaucoma and primary open-angle glaucoma. Int Ophthalmol. doi:10.1007/s10792-014-0020-Z

2. Galgauskas S, Norvydaite D, Krasauskaite D, Stech S, Asoklis RS (2013) Age-related changes in corneal thickness and endothelial characteristics. Clinical Interv Aging 8: 1445-1450. doi:10.2147/cia.s51693

\section{Y. C. Kim $(\bowtie)$}

Department of Ophthalmology, Dongsan Medical Center, Keimyung University School of Medicine, Daegu, Korea e-mail: eyedr@dsmc.or.kr 